\title{
ALBINIANA GEN.N. E REVALIDAÇÃO DE ALOCHA MELICHAR (HOMOPTERA, CICADELLIDAE, CICADELLINAE) ${ }^{1}$
}

\author{
Rodney R. Cavichioli ${ }^{2}$
}

\begin{abstract}
Albiniana GeN.N. AND REVAlidation OF Alocila MLlichar (Homoptera, Cicadellidae, Cicadellinae). The genus Alocha Melichar, 1926 (type species: Tettigonia sordida Signoret, 1855) is revalidated. The foollowing new combinations are established: Alocha lugubris (Young, 1977), A. propria (Young, 1977) and A. rossi (Young, 1977), A. sordida (Signoret, 1855) is a comb. rev. A new genus, Albiniana (type-species: Paromenia weyrauchi Young, 1977), is described.

KEY WORDS. Cicadellidae, Cicadellinae, Alocha, Albiniana, Neotropical
\end{abstract}

Em estudo prévio do grupo Paromenia Young, 1977, realizado pelo presente autor, o grupo é composto por 11 gêneros (YOUNG 1977), destes foram examinados 10. O agrupamento é monofilético, porém, o gênero Paromenia não o é, sendo que Paromenia weyrauchi Young, 1977 e as espécies aqui transferidas para Alocha Melichar, 1926 compartilham o caráter "margem apical do anteclípeo truncado", enquanto que, nas demais espécies de Paromenia é convexo. A conseqüente revalidação de Alocha foi determinada pelo não compartilhamento do caráter apresentado na discussão do gênero Alocha.

\section{Alocha Melichar, 1926, gen. rev.}

Figs 1-15

Alocha Melichar, 1926: 342.

Scarisana Metcalf, 1949; espécie-tipo: Scarisana variabilis Metcalf, 1949.

Espécie-tipo: Tettigonia sordida Signoret, 1855 (designação subseqüente: China, 1938).

Diagnose. Cabeça levemente pronunciada, com a margem anterior arredondada, ocelos proemeninetes, lóbulos suprantenais, em vista dorsal, levemente proeminentes; pronoto tão largo quanto a largura da cabeça; tégminas com venação distinta, com quatro células apicais e três células anteapicais fechadas, a base da terceira mais proximal do que o ápice do clavo e as duas adjacentes com a base na altura do ápice do clavo.

Descrição. Comprimento total: 10-11,5mm. Cabeça levemente pronunciada, com a margem anterior arredondada, sem carena na transição entre a coroa e a face; superfície dorsal plano-convexa; ocelos proeminentes, posicionados sobre a linha

1) Contribuição número 956 do Departamento de Zoologia, Universidade Federal do Paraná.

2) Departamento de Zoologia, Universidade Federal do Paraná. Caixa Postal 19020, 81531-990 Curitiba, Paraná, Brasil. Pesquisador do CNPq. 
imaginária que tangencia os bordos anteriores dos olhos; lóbulos suprantenais, em vista dorsal, levemente proeminentes, em vista lateral, oblíquos, convexos e não carenados; clípeo em vista frontal levemente achatado medianamente, de perfil convexo, com uma leve angulação no terço apical; sutura transclipeal incompleta; anteclípeo de perfil contínuo ao ápice do clípeo, com a margem apical convexa. Pronoto tão largo quanto a largura da cabeça, com as margens laterais convergentes anteriormente; margem posterior mais ou menos reta; superfície dorsal lisa; tégminas com comprimento quatro vezes maior do que sua maior largura; venação distinta, com veias não elevadas, sem plexo de veias anteapicais, veias extranumerárias ausentes no cório e no clavo, com quatro células apicais, base da quarta célula apical mais proximal, a base da terceira, com três células anteapicais fechadas, a base da célula anteapical externa mais proximal do que o ápice do clavo, superfície das tégminas lisa; asas posteriores com $\mathrm{S}_{1+2}$ incompleta, não formando a primeira célula apical. Pernas posteriores com a junção fêmur-tíbia atingindo a base do proepimenro, quando em repouso; fórmula setal dos fêmures posteriores 2.1.1; basitarsos posteriores com comprimento maior do que a soma dos dois distais; superfície plantar com fileiras de microcerdas.

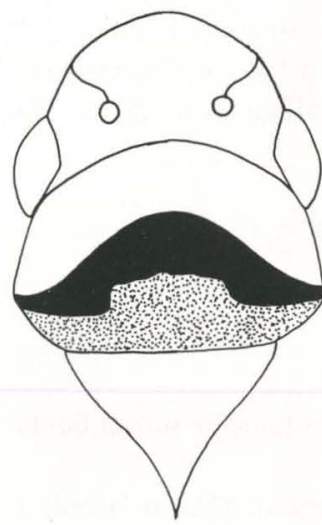

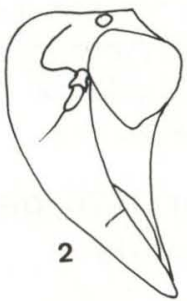
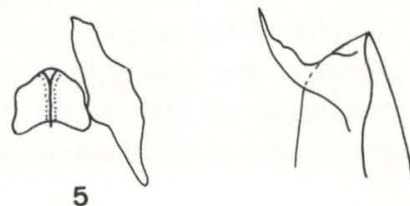

6

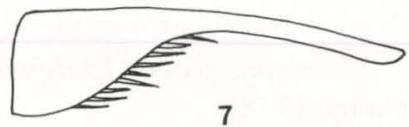

1

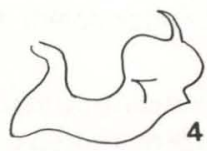

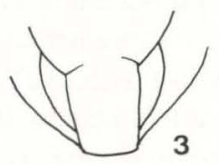

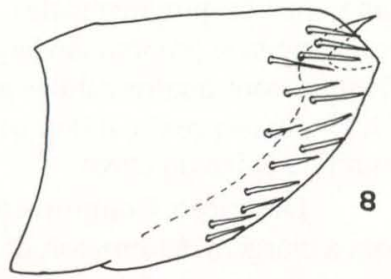

Figs 1-8. Alocha sordida (Signoret, 1855). (1) Cabeça, pronoto e escutelo, em vista dorsal; (2) cabeça em vista lateral; (3) ápice do clipeo e anteclípeo, em vista frontal; (4) edeago em vista lateral; (5) parâmero e conetivo, em vista dorsal; (6) ápice do pigóforo do macho, em vista dorsal; (7) placa subgenital, em vista ventral; (8) pigóforo do macho, em vista lateral. 

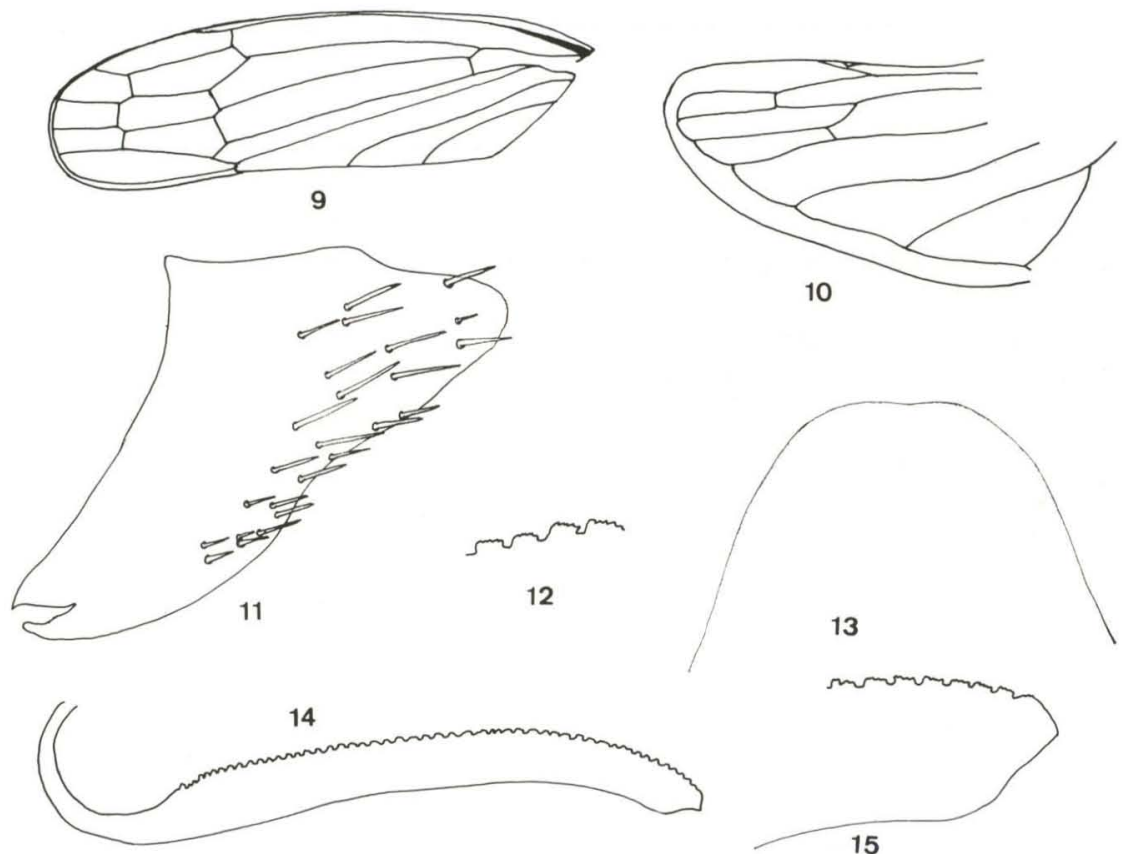

13

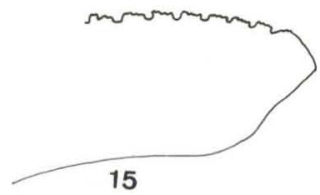

Figs 9-15. Alocha sordida (Signoret, 1855). (9) Tégmina esquerda; (10) asa posterior esquerda; (11) pigóforo da fêmea, em vista lateral; (12) margem superior da segunda valva do ovopositor; (13) vii esternito da fêmea; (14) segunda valva do ovopositor; (15) ápice da segunda valva do ovopositor.

Genitália do macho. Pigóforo alongado, com a margem posterior truncada ou levemente angulada (variação interespecífica), com ou sem processos, com macrocerdas distribuídas no terço apical; placa subgenital triangular, alongado ou não, com o ápice obtuso; com uma fileira de macrocerdas distribuidas nas margens laterais; estilos mais ou menos longos, com o ápice truncado, em forma de pé e voltados para fora ou dirigido posteriormente, com um lobo pré-apical; conetivo em barra ou subquadrangular, com carena dorsal mediana; edeago subcilíndrico, longo ou curto, variando interespecificamente, com processos apicais; paráfise ausentes.

Genitália da fềmea. Pigóforo tão longo quanto sua largura basal, com a margem posterior angulad, com macrocerdas distribuídas no terço apical; vii esternito levemente alongado ou curto, com a margem posterior convexa ou emarginada; segunda valva do ovipositor com o ápice voltado para baixo e margem apico-ventral côncava.

Discussão. O gênero Alocha foi descrito por Melichar (1926); Young (1977), considerou-o sinônimo de Paromenia Melichar, 1926. No presente estudo, três espécies de Paromenia ( $P$. sordida, $P$. rossi e P.lugubris), formam um grupo monofilético, tendo como grupo-irmão a espécie $P$. weyrauchi Young, 1977. Estas 
quatro espécies, separam-se das demais de Paromenia por apresentarem a margem apical do anteclípeo truncada e não compartilhando o estado, coroa com concavidade transversa anterior aos ocelos, que reune as demais espécies de Paromenia com Onega Distant, 1908. O parentesco de Alocha sordida, A. rossi e A. lugubris é definido pela sinapomorfia "pronoto tão largo quanto a largura da cabeça", o que permitiu a revalidação do gênero Alocha, o qual está relacionado com gênero Albiniana gênero novo, pelos caracteres comentados acima. A espécie $P$. propria Young, 1977 foi incluída em Alocha por compartilhar com os mesmos estados de caracteres de $A$. sordida, $A$. rossi e $A$. lugubris.

Espécies do gênero:

A. lugubris (Young, 1977), comb.n.

A. propria (Young, 1977), comb.n. (Tipo não examinado)

A. rossi (Young, 1977), comb.n.

A. sordida (Signoret, 1855), comb.n.

S. variabilis (Metcalf, 1949).

\section{Albiniana gen.n.}

Figs 16-29

Espécie-tipo. Paromenia weyrauchi Young, 1977.

Diagnose. Cabeça levemente pronunciada, com a margem anterior arredonda, ocelos fortemente proeminentes, situados sobre a linha imaginária que tangencia os bordos anteriores dos olhos; pronoto tão largo quanto a largura da cabeça e com as margens laterais convergentes anteriormente; tégminas com venação distinta, com quatro células apicais e três anteapicais, a base a externa mais proximal do que o ápice do clavo, as demais adjacentes ao ápice do clavo.

Descrição. Comprimento total: $10-13 \mathrm{~mm}$. Cabeça levemente pronunciada, com a margem anterior arredondada, sem carena na transição entre a coroa e a face; superfície dorsal plano-convexa e lisa; ocelos fortemente proeminentes, posicionados sobre a linha imaginária que tangencia os bordos anteriores dos olhos; lóbulos suprantenais, em vista dorsal, levemente proeminentes, em vista lateral, oblíquos, convexos e não carenados; clípeo em vista frontal levemente achatado medianamente, de perfil convexo, com uma leve angulação no terço apical; sutura transclipeal incompleta; anteclípeo de perfil contínuo ao ápice do clípeo, com a margem apical truncada. Pronoto tão largo quanto a largura da cabeça, com as margens laterais convergentes anteriormente; margem posterior mais ou menos reta; superfície dorsal lisa; tégminas com comprimento quatro vezes maior do que sua maior largura; venação distinta, com veias não elevadas, sem plexo de veias anteapicais, veias extranumerárias ausentes no cório e no clavo, com quatro células apicais, base da quarta célula apical mais proximal do que a base da terceira, com três células anteapicais fechadas, a base da célula anteapical externa mais proximal do que o ápice do clavo, superfície das tégminas lisa; asas posteriores com $\mathrm{S}_{1+2}$ incompleta, não formando a primeira célula apical. Pernas posteriores com a junção fêmur-tíbia atingindo a base do proepimenro, quando em repouso; fórmula setal dos fêmures posteriores 2.1.1; basitarsos posteriores com comprimento maior do que a soma dos dois distais; superfície plantar com fileiras de microcerdas. 

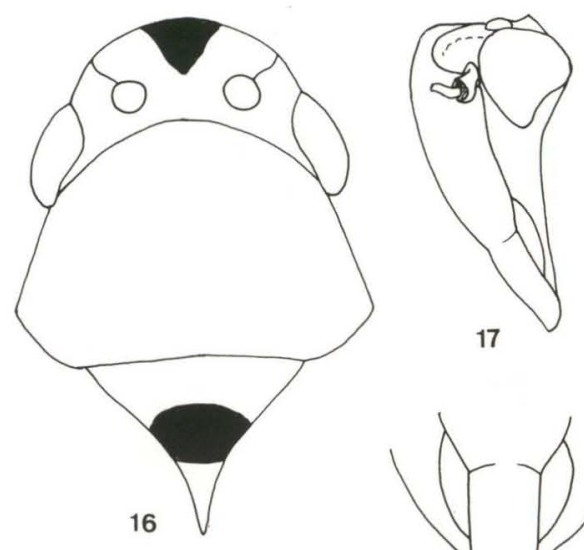

17

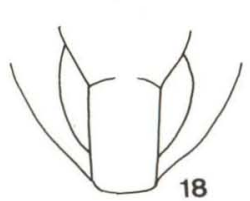

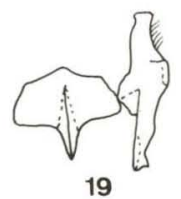
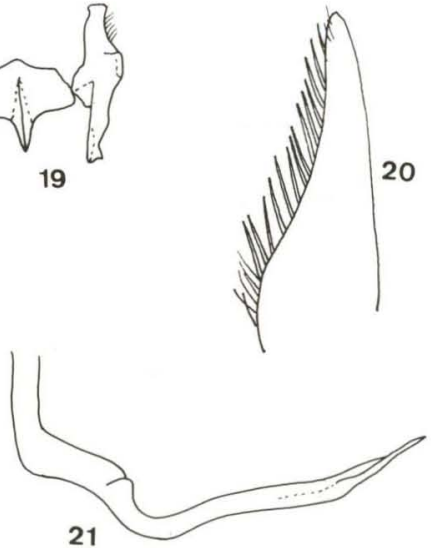

21

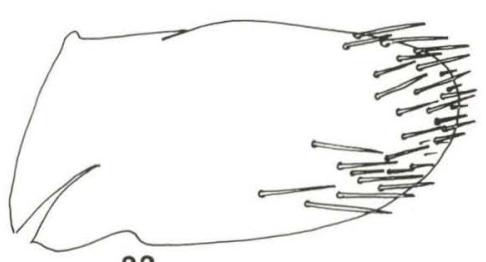

22

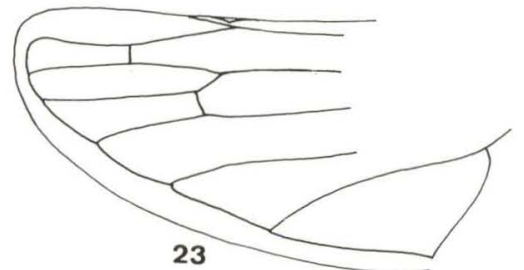

Figs 16-23. Albiniana weyrauchi (Young, 1977). (16) Cabeça, pronoto e escutelo, em vista dorsal; (17) cabeça em vista lateral; (18) Ápice do clipeo e anteclipeo, em vista frontal; (19) parâmero e conetivo, em vista dorsal; (20) placa subgenital, em vista ventral; (21) edeago em vista lateral; (22) pigóforo do macho, em vista lateral: (23) asa posterior esquerda.

Genitália do macho. Pigóforo mais longo do que sua largura basal, com a margem posterior convexa, sem processos, com macrocerdas distribuídas no terço apical; placa subgenital triangular, com o ápice obtuso, com uma fileira de macrocerdas distribuidas nas margens laterais; estilos longos, com o ápice truncado ou arredondado e voltados para posteriormente ou para fora, com um lobo pré-apical; conetivo em subquadrangular, com carena dorsal mediana; edeago suubcilíndrico, longo, com a base estreita e ápice formando um processo agudo; paráfise ausente.

Genitália da fêmea. Pigóforo tão longo quanto sua largura basal, com a margem posterior angulada, com macrocerdas distribuídas ao longo da sua margem posterior; vii esternito alongado, com a margem posterior subparabólica; segunda valva do ovipositor com o ápice voltado para baixo e margem apico-ventral côncava.

Discussão. Está espécie é grupo-irmão de Alocha Melichar, porém se distingue pela autapomorfia "ocelos fortemente proeminentes". A proposta de criação de um novo gênero para esta espécie se dá em função dessa autapomorfia e, por compartilhar com Alocha o caráter margem apical do anteclípeo truncada, separando-as das outras espécies de Paromenia. 
A identificação de $A$. weyrauchi (Young, 1977) foi feita pela descrição original (YOUNG 1977) e por diapositivo do holótipo. Não foi possível examinar o holótipo por não ter sido encontrado no National Museum of Natural History de Washington, segundo o Dr. Thomas J. Henry.

Espécie do gênero: Albiniana weyrauchi (Young, 1977), comb.n.

O gênero Albiniana é dedicado ao Prof. Dr. Albino Morimasa Sakakibara, pela amizade e orientação.
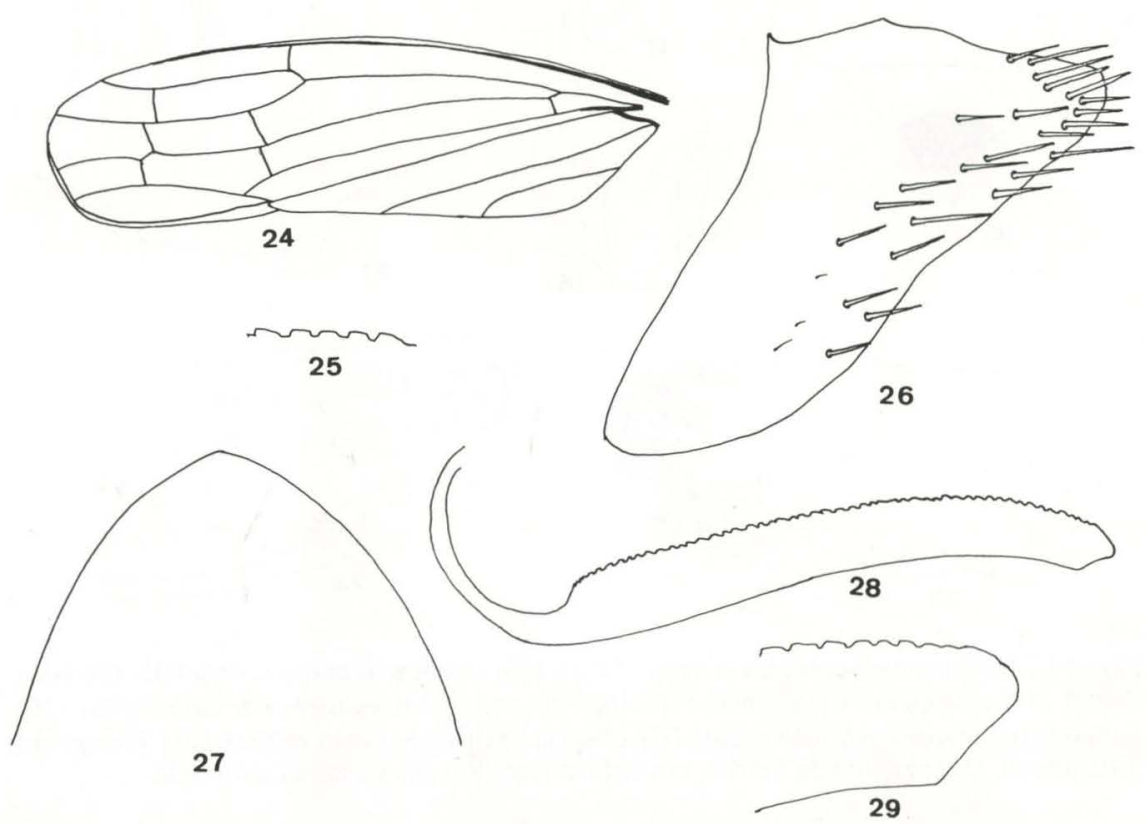

Figs 24-29. Albiniana weyrauchi (Young, 1977); (24) Tégmina esquerda; (25) margem superior da segunda valva do ovopositor; (26) pigóforo da fêmea, em vista lateral; (27) VII esternito da fêmea; (28) segunda valva do ovopositor; (29) ápice da segunda valva do ovopositor.

AGRADECIMENTOS. Ao Dr. Mick D. Webb do The Natural History Museum (BMNH) de Londres, Dr. Thomas J. Henry do National Museum of Natural History (USNM) de Washington, Dr. Pedro Lozada da Universidad de San Marcos, Dr. Ulrike Aspock do Naturhistoriches Museum de Viena, Dr. J. Deckert e Dr. Kurt K. Günther do Museum für Naturkunder der Humboldt Universität de Berlin pelo empréstimo de material.

\section{REFERÊNCIAS BIBLIOGRÁFICAS}

Melichar, L. 1926. Monographie der Cicadellinen. III. Ann. Mus. Nat. Hungarici 23: 273-394.

Signoret, V. 1853. Revue Iconographique des Tettigonides. Ann. Soc. Ent. Fr. 1: 323-374. 
1855. Revue Iconographique des Tettigonides. Ann. Soc. Ent. Fr. 3: 765-836,

YounG, D.A. 1964. Some cicadelline types of species described by Signoret from Berlin collections. Mitt. Zool. Mus. Berlin 40: 9-13. 1977. Taxonomic study of the Cicadellinae (Homoptera; Cicadellidae), Part 2, New World Cicadellini and the genus Cicadella. USDA Tech. Bull. 239: $1-1135$.

Recebido em 30.X.1995; aceito em 18.XI.1996. 